\title{
Исследование влияния защиты компаундом СИЭЛ на стабильность функционирования контрольно- измерительных МЭМС-сенсоров
}

\author{
П. Григорьев ${ }^{1}$, С. Милешин ${ }^{2}$, Т. Цивинская ${ }^{3}$
}

\begin{abstract}
В настоящее время наблюдается качественный скачок в области точного приборостроения, обусловленный активным внедрением новых принципов измерения физических величин и методик обработки выходных сигналов с применением наработок в области микроэлектроники [1]. Можно утверждать, что происходит процесс слияния приборостроения и микроэлектроники: сенсоры, измеряющие самые разные физические параметры, изготавливаются в виде структуры, формируемой на полупроводниковом кристалле. Однако этот процесс наталкивается на значительные трудности, связанные с отличием некоторых требований к материалам и технологическим процессам, способным обеспечить стабильное производство качественных МЭМСсенсоров, от аналогичных факторов производства традиционных интегральных микросхем. В статье рассматривается один из таких проблемных процессов защита пьезорезистивных сенсоров на базе монокристаллического кремния от воздействия окружающей среды.
\end{abstract}

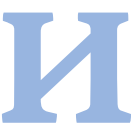
нтерес к датчикам на базе монокристаллического кремния то возрастает, то идет на спад. Объяснение простое: датчики очень востребованы, их конструкция и технология сборки на первый взгляд не представляются сложными, большинство технологий в микроэлектронной индустрии отработаны; тем не менее освоить выпуск надежных и дешевых устройств этого класса не получается. Почему? Ответ прост: разработчики рассматривают МЭМС-датчики как изделия микроэлектроники и пытаются без какой-либо адаптации перенести отработанные для микросхем технологии сборки на производство датчиков.

Но функции изделия из монокристаллического кремния в микроэлектронике и приборостроении совершенно разные; соответственно, различными должны быть требования к качеству применяемых материалов и подходы к разработке технологии сборки. Истоки проблемы лежат в коренном различии роли полупроводникового кристалла: в изделиях "классической" микроэлектроники схемы на кристалле выполняют задачи обработки

Мгту им. Н.Э. Баумана, ассистент, grigorevpv@gmail.com.

мгту им. Н.Э. Баумана, ассистент, info@iu4.bmstu.ru.

ООО "Сенсорные системы МгтУ им. Н. Э. Баумана", главный технолог, tsivinskaya_t@mail.ru. электрического сигнала, а в датчиках, где кристалл реализует функцию чувствительного элемента, он является измерительным инструментом, работающим с тем или иным параметром внешней среды [2]. Причем для обеспечения возможности использования в составе контрольно-измерительных приборов датчик должен обладать высокой чувствительностью; в нашем случае, то есть применительно к пьезорезистивным датчикам, - чувствительностью к механическим напряжениям. От него также требуется высокая стабильность среды формирования выходного сигнала.

\section{ЧТО ТАКОЕ ПЬЕЗОРЕЗИСТИВНЫЙ СЕНСОР?}

Во время освоения технологий формирования электронных элементов на поверхностном слое кремния выяснился ряд свойств этого материала, создающих предпосылки для разработки миниатюрных высокоточных сенсоров измерения физических величин, связанных с тензорезистивным эффектом: идеальная упругость и прямолинейная зависимость выходного электрического сигнала от механического воздействия и абсолютно точное повторение механического действия от поданного сигнала [2]. С технологической точки зрения благоприятным фактором стала возможность получать нужные структуры путем объемного травления 

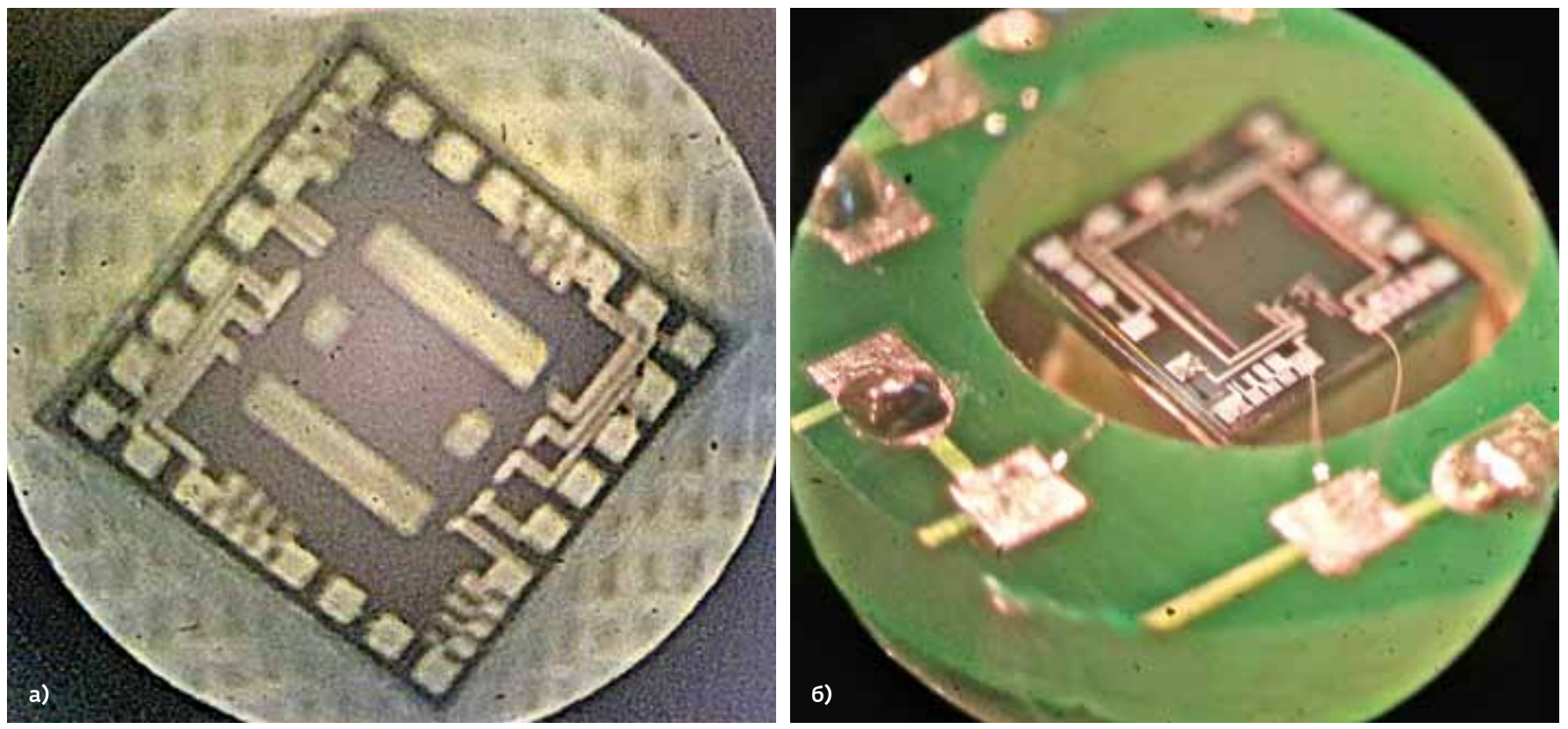

Рис. 1. Чувствительный элемент пьезорезистивного сенсора, сконфигурированный для разных задач: а - для измерения параметров вибрации; 6 - для измерения давления (установлен в корпус). Фотографии сделаны в лабораторных условиях через окуляр микроскопа

в химических растворах. На основе монокристаллического кремния разработаны кристаллы пьезорезистивных сенсоров с чувствительным элементом, который может иметь конфигурацию, оптимальную для каждого вида механического воздействия: давления, вибрации, ускорения и т. п. (рис. 1)

Конструктивно чувствительный элемент представляет собой тонкий кристалл монокристаллического кремния, на планарной (лицевой) стороне которого в расчетных точках максимального механического напряжения сформированы тензорезисторы, объединенные токопроводящими дорожками в мостовую схему; по одной диагонали моста к дорожкам подключается питание, со второй диагонали снимается сигнал [3]. Иногда с целью схемотехнической корректировки сигнала на поверхности кристалла формируются дополнительные цепи, - например, транзисторная схема термокомпенсации, - или вводятся дополнительные элементы, позволяющие получать более обширную информацию о состоянии кристалла - например, терморезисторы, дающие информацию для повышения точностных характеристик выходного сигнала средствами программной коррекции

Для проведения замеров чувствительный элемент сенсора, сформированный в поверхностном слое кремния, должен контактировать с измеряемой средой. Неблагоприятная среда способна разрушить структуру материалов, из которых состоят компоненты интегральной схемы. Отсюда следует необходимость защиты сенсора тем или иным способом, но обязательно так, чтобы измеряемый параметр среды не искажался защитным материалом и / или элементом конструкции.

\section{ЗАЩИТА СЕНСОРА КРЕМНИЙОРГАНИЧЕСКИМИ КОМПАУНДАМ И}

При сборке пьезорезистивных датчиков большинство операций заимствовано из технологических процессов микроэлектроники, и одна из них - защита поверхности кристалла от воздействия внешней среды посредством покрытия кремнийорганическими компаундами.

Кремнийорганические компаунды обладают высокой термостойкостью, низким содержанием примесей и хорошими электрофизическими характеристиками. Но вместе с тем эти материалы имеют сравнительно высокую влагопроницаемость [4] и низкую адгезию к защищаемым поверхностям, что создает условия для появления электролита на границе соприкосновения кремния и компаунда, приводя впоследствии к коррозии металлических проводников.

В ходе экспериментальной работы «Исследование влияния защитных кремнийорганических материалов на коррозию алюминиевой металлизации интегральных схем" [4] было изучено развитие коррозии алюминиевой металлизации в условиях повышенной влажности и температуры при применении в качестве защитного покрытия ряда кремнийорганических компаундов. Вторым направлением работы стало рассмотрение влияния компонентов покрытия на коррозионную активность на примере компаундов типа СИЭЛ, представляющих собой композиции 
на основе низкомолекулярных кремнийорганических олигомеров с различными добавками [4]. Было установлено, что наибольшую коррозионную стойкость металлизации обеспечивают компаунды СИЭЛ159-322А и СИЭЛ159-356Б, которые стали предметом дальнейшего, более глубокого изучения авторами статьи.

Специально для заливки тензочувствительных элементов (датчиков давления, перемещения, силы и т.д.) был разработан эластичный заливочный компаунд СИЭл159-356Б. Полимеризованный компаунд представляет собой гелеобразный продукт, обладающий свойством самозалечивания и сохраняющий работоспособность в температурном диапазоне от -120 до $200^{\circ} \mathrm{C}$. Компаунд состоит из двух компонентов; варьируя их соотношение, добиваются нужной вязкости покрытия, наилучшее значение которой для заливки чувствительных элементов датчиков давления составляет 500 сПз. (0,5 Па·с).

Защитное действие компаунда СИЭЛ 159-356Б, как и других кремнийорганических композиций, обусловлено реакцией хемосорбции. Поверхность кристалла химически активна, что объясняется присутствием на ней активных молекул типа $\mathrm{NO}_{2}, \mathrm{SO}_{2}$ и групп типа - $\mathrm{CH}_{3}-$ остатков высокомолекулярных соединений, используемыхпри формировании интегральной схемы. Высокомолекулярные соединения в составе компаунда также имеют открытые связи, поэтому при нанесении компаунда начинается химическая реакция, в результате которой на поверхности образуется монослой адсорбированных молекул, прочно сцепленных с поверхностью кристалла.

Следует отметить, что для хемосорбции характерно наличие активационного барьера, поэтому при повышении температуры хемосорбция ускоряется. Исследование этого аспекта технологии нанесения покрытия показало, что для достижения максимальной адгезии компаунда необходимо активизировать поверхность кристалла путем вакуумирования при температуре не менее $150^{\circ} \mathrm{C}$; кроме того, в этом режиме эффективно удаляются следы влаги.

Одним из основных источников массовых дефектов, которые наблюдались в ходе многочисленных попыток организации изготовления кремниевых МЭМС-сенсоров, стала технология нанесения компаунда. Большинство операций в производстве изделий микроэлектроники автоматизировано, и для нанесения компаунда на кристалл, как правило, используется широко известный и достаточно удобный технологический процесс - капельное дозирование. При этом на поверхности кристалла образуется слой компаунда, имеющий форму, показанную на рис. 2.

Нанесенное толстым слоем на ограниченной площади покрытие, полимеризуясь неравномерно по объему, испытывает термическую усадку - стремится сжаться. В объеме полимера возникают внутренние напряжения, наибольшие их значения наблюдаются у края полимерного слоя [5]. Особенно велики и опасны касательные

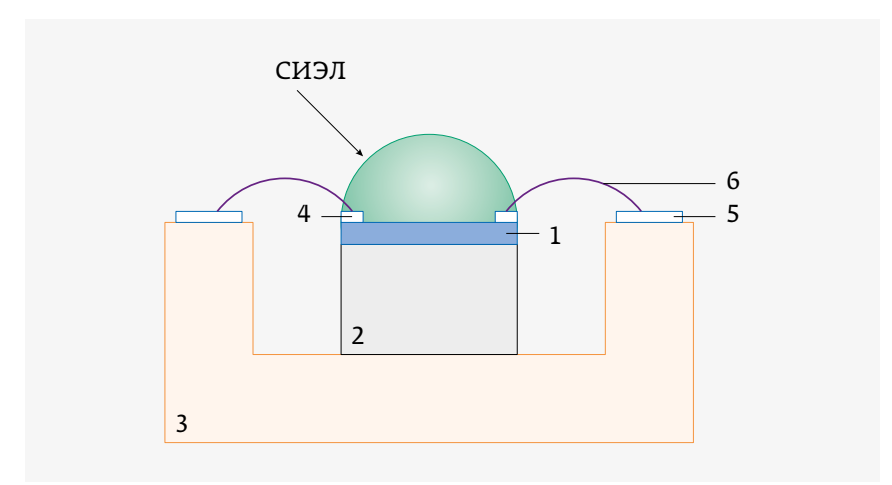

Рис. 2. Форма, приобретаемая защитным полимером при нанесении его методом капельного дозирования: 1 - кристалл; 2 - стеклянная подложка; 3 - корпус; 4 - контактные площадки кристалла; 5 - контактные площадки корпуса, 6 - проводники

напряжения, действующие в плоскости сопряжения полимера и поверхности кристалла [5]. Зона шириной 0,3 мм у края кристалла является местом наибольшей их концентрации, и в ней могут образовываться зазоры между кристаллом и покрытием.

Для обычных микросхем это грозит обрывами проводников и, при попадании влаги, образованием между покрытием и поверхностью кристалла токопроводящего слоя, способного повредить элементы электрической схемы. В случае сенсорного кристалла проблема еще более радикальна: он теряет даже принципиальную способность функционировать. Чувствительные пьезорезисторы в поверхностном слое кремния через переходной монослой сцеплены со всем массивом компаунда. Механические напряжения от усадки тем выше, чем толще слой компаунда; при нанесении его методом капельного дозирования самые высокие значения напряжения приходятся на центр кристалла, то есть на его рабочую часть, и в результате датчик выдает сигнал при отсутствии внешнего воздействия, которое он должен измерять. К тому же эти напряжения могут изменяться в процессе старения компаунда, под влиянием температуры, поэтому скомпенсировать их невозможно.

Увеличение вязкости полимера не решает указанную проблему. Тем не менее сделать защиту компаундом СИЭл 159-356Б гарантированно работоспособной реально - для этого надо изменить технологию заливки (рис. 3).

Улучшенный способ заливки состоит в том, что компаунд наносится на кристалл не каплей, а тонкой пленкой - слоем толщиной не более 100 мкм. В процессе нанесения он равномерно и плавно стекает по боковым поверхностям чувствительного элемента, обволакивая их; изделие в это время должно быть нагрето до температуры 100-120 ․ В процессе полимеризации благодаря реакции хемосорбции первый и последующие слои компаунда 


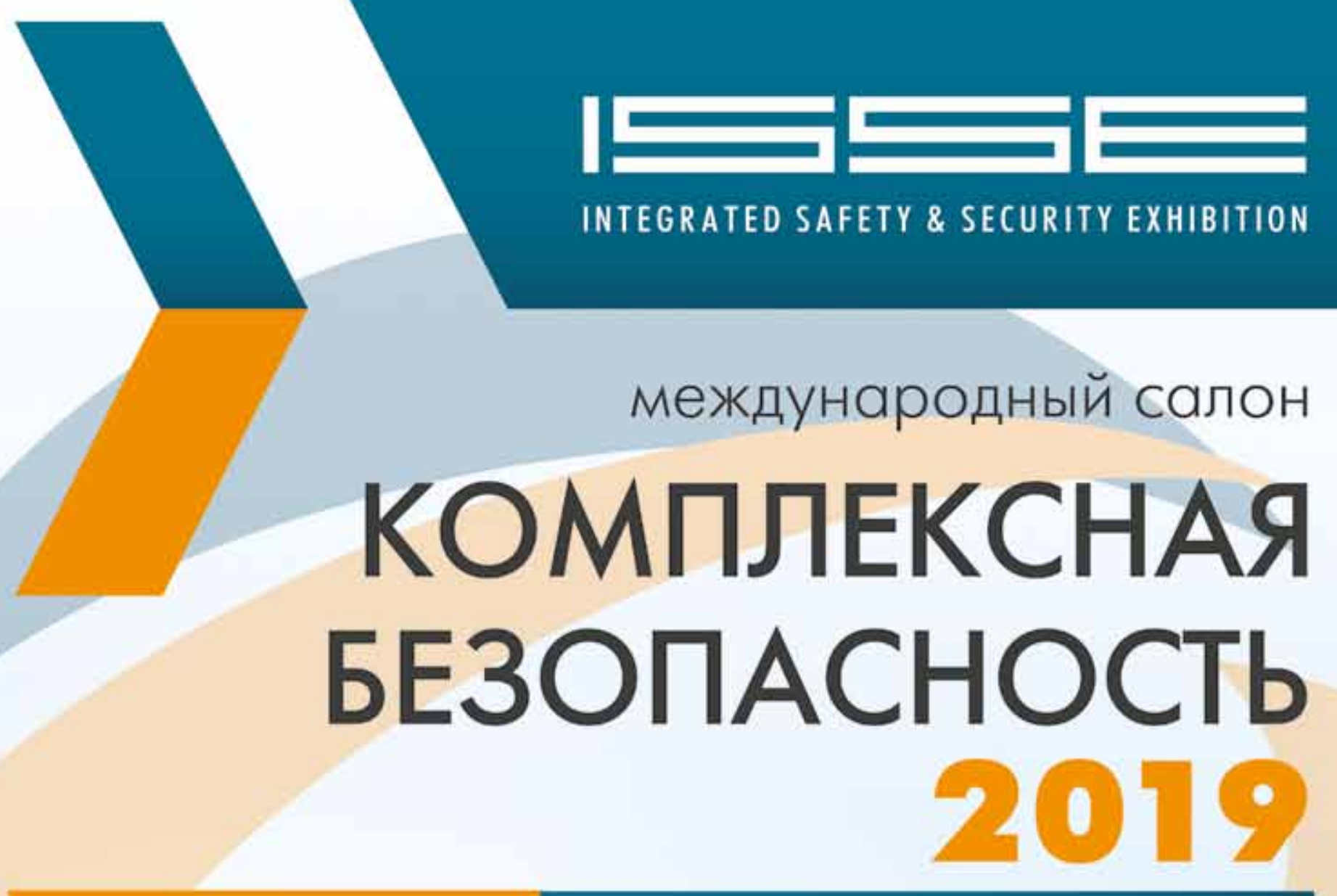

\section{Москва, ВДНХ Павильон №75}

$$
\text { 5-7 июня }
$$

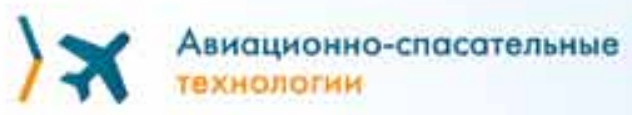

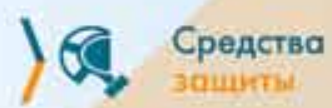

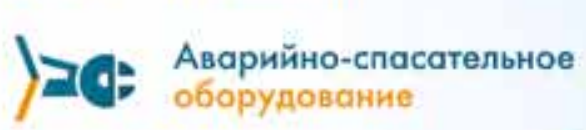

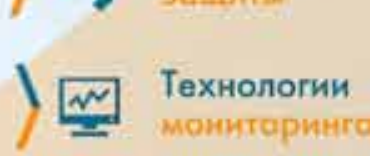

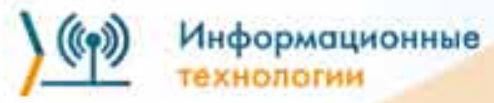

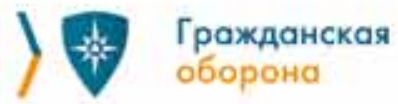

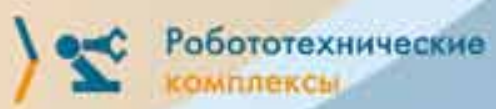

Ногинский спасательный
центр МЧС России

8 июня

Организатор

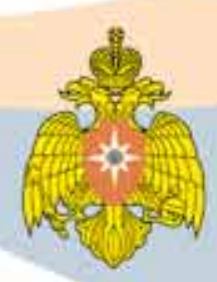

Министерство Россииской Федерочин по делам гражданской оборомы, чрезвычайным ситуациям и ликеидации поспедствий стихийных бедствий
Министерство внутренних деп Российской Федерсции 


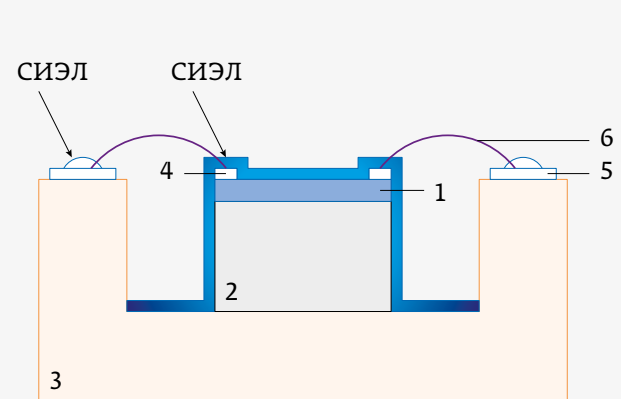

Рис. 3. Метод заливки кристалла гелем Сиэл 159-356Б, разработанный участниками исследования: 1 - кристалл; 2 - стеклянная подложка; 3 - корпус; 4 - контактные площадки кристалла; 5 - контактные площадки корпуса; 6 - проводники

образуют плотную пленку без пор и трещин, так что даже в пленках толщиной менее 100 мкм защитные свойства геля очень высоки. Практика выпуска линейки датчиков давления марки ИПИД с использованием пленочной технологии нанесения покрытия СИЭЛ 159-356Б показала, что компаунд не влияет на чувствительность и точность измерения датчиков в диапазоне давлений от 1 Па до 60 МПа, при работе условиях повышенной влажности, контакте с бензином, маслами и т.д.

\section{РАЗДЕЛИТЕЛЬНАЯ МЕМБРАНА - ЗАЩИТА ОТ ВОЗДЕЙСТВИЯ АГРЕССИВНОЙ СРЕДЫ}

Промышленным датчикам приходится работать не только в условиях загрязнений или в контакте с различными растворителями, но и в разного рода агрессивных средах. В таких случаях в качестве защиты чувствительной поверхности кристалла, не увеличивающей погрешность измерений и не ухудшающей быстродействие прибора, принято использовать специальный элемент конструкции датчика - разделительную металлическую мембрану, полностью изолирующую измерительную МЭМС-структуру от внешней среды.

Для передачи давления от металлической мембраны к измерительным элементам в приборостроении с давних времен применяются жидкости типа ПФМС. Эти жидкости обладают отличными техническими характеристиками: они химически инертны, хорошо проводят тепло, способны работать при температуре до $300^{\circ} \mathrm{C}$; при этом у них достаточно низкая стоимость. Неудивительно, что их пробовали и пробуют по сей день использовать при разработке датчиков с разделительной мембраной на базе пьезорезистивных сенсоров. Результаты всегда оказывались неутешительными.

В ходе проведенных авторами работ датчики заполнялись жидкостью ПФМС-4. Во время испытаний при повышении температуры ихсигнал или пропадал, или начинал «плыть» - постоянно менял значения. При исследовании дефекта был зафиксирован обрыв проволоки, разваренной между контактными площадками кристалла и переходной платы. Концы провода были оплавлены: жидкость вступала в реакцию с поверхностью кристалла, и на ней образовывался слой электролита, который вызывал замыкание между проводниками.

В следующей серии экспериментов использовались кристаллы, покрытые компаундом СИЭл 159-356Б. Защита не помогла: после нагрева до температуры $85^{\circ} \mathrm{C}$ из строя вышли 80\% датчиков. В этом случае дефект выглядел следующим образом: при подаче малых давлений сигнал с датчика отсутствовал, появляясь только при пятикратном превышении верхнего значения измерительного диапазона; после снятия нагрузки датчик в начальное состояние не возвращался.

Анализ дефекта показал следующее: жидкость вступала в реакцию хемосорбции с компаундом, между их молекулами образовывались связи. Компаунд набухал, а количество свободной жидкости соответственно уменьшалось. Между поверхностью жидкости и защитной мембраной образовывался зазор значительно большей величины, чем максимальный расчетный прогиб мембраны, не превышающий 0,1 мм. В результате металлическая мембрана необратимо деформировалась, теряя упругие свойства.

Вывод однозначен: использовать кремнийорганические жидкости для заполнения датчиков давления с чувствительным элементом на основе монокристаллического кремния нельзя - ни в случае "открытого" сенсора, ни при использовании защиты компаундом СИЭЛ159-356Б.
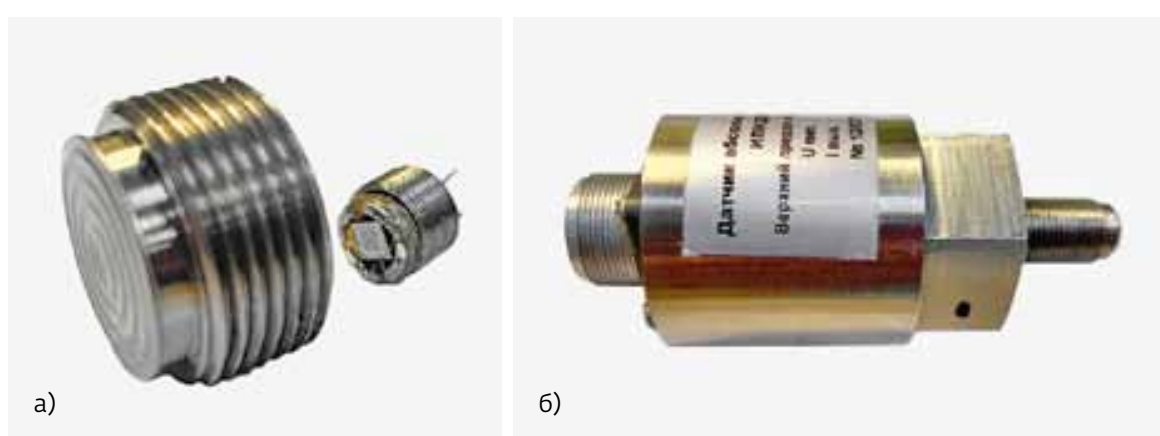

Рис. 4. Широкодиапазонный датчик давления газовой и жидкой среды, разработанный в МГтУ им. Н. Э. Баумана: а - измерительная головка с кристаллом сенсора (справа) и корпус измерительного узла с разделительной мембраной; б - датчик в сборе 


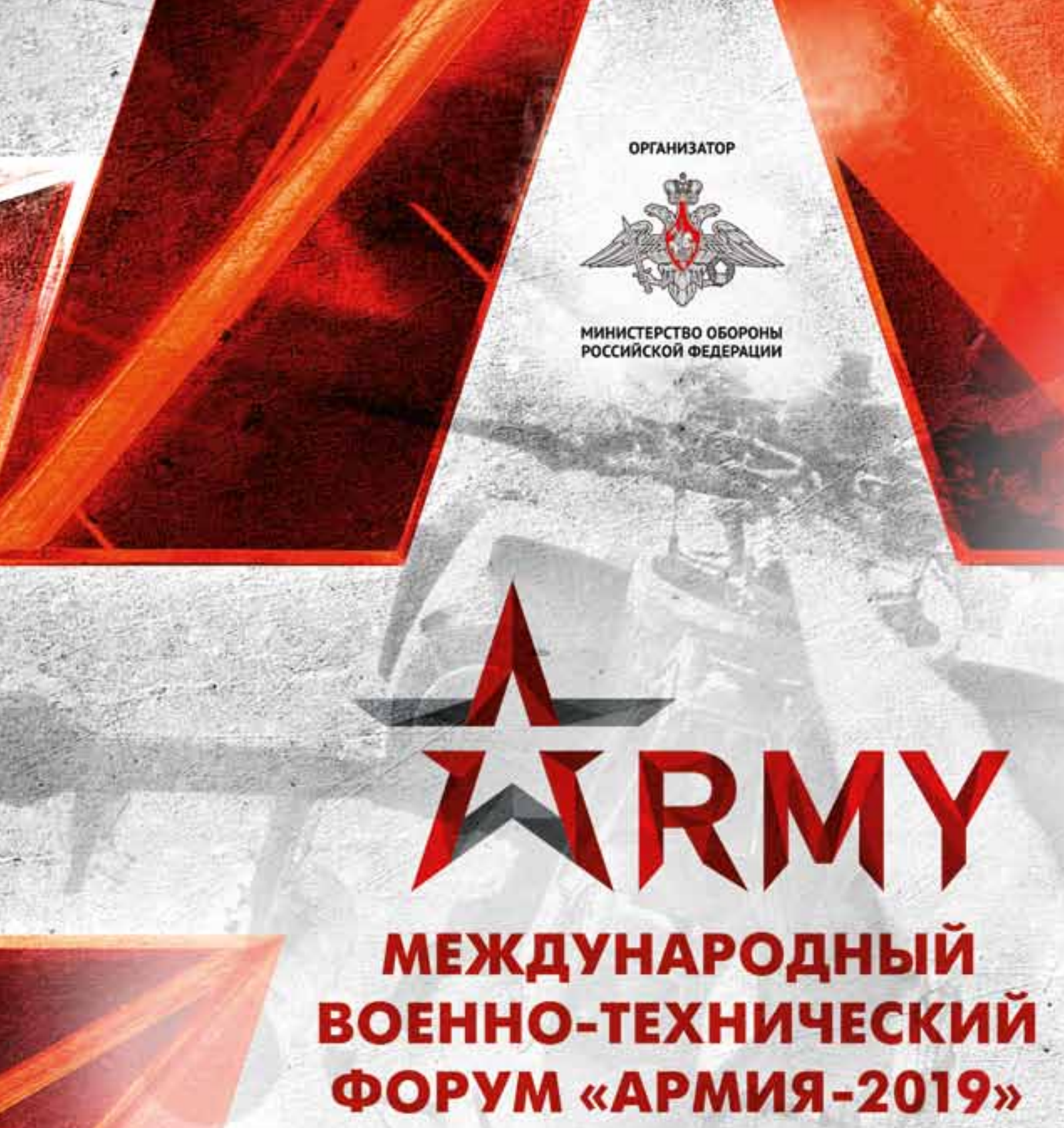

\section{5-30 Июня ПАТРИОТ ЭКСПО}

WWW.RUSARMYEXPO.RU

ВЫСТАВОЧНЫЙ ОПЕРАТОР

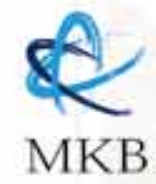

МЕЖДУНАРОДНЫЕ КОНГРЕССЫ И ВЫСТАВКИ 
Причина неизбежных отказов заключена в химическом составе таких жидкостей: он в своей основе тот же, что и у СИЭЛ159-356Б, и у растворов, используемых при формировании интегральных схем на кремнии. Поэтому кремнийорганическая жидкость действует как растворитель, вступая в реакцию с активными осколками больших молекул из состава компаунда и поверхности самого кристалла.

Альтернативой кремнийорганическим жидкостям являются фторорганические [5], представляющие собой молекулярные соединения, подобные кремнийорганическим, в которых атомы кремния полностью заменены атомами фтора. Фтор - активный химический элемент, он образует чрезвычайно устойчивую связь с углеродом, что обеспечивает этим веществам высокую степень химической инертности. Фторорганические жидкости негорючи, мало гигроскопичны, имеют низкий уровень диэлектрических потерь, нагревостойкость до $500^{\circ} \mathrm{C}$ при стабильности свойств в температурном диапазоне от -60 до $300^{\circ} \mathrm{C}$.

Экспериментально была проверена фторорганическая жидкость БЛ-П ТУб-01-935-89. Образцы чувствительных элементов датчиков давления типа ИПИдм были выдержаны при температуре $125^{\circ} \mathrm{C}$ в течение 72 ч в технологической таре с жидкостью БЛ-П. Их осмотр при 56-кратном увеличении показал, что защитный слой компаунда

\section{ЗАО "Руднев-Шиляев" \\ 口 paspa

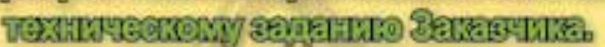

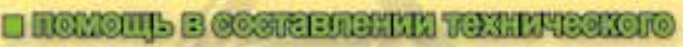

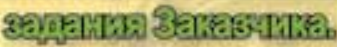
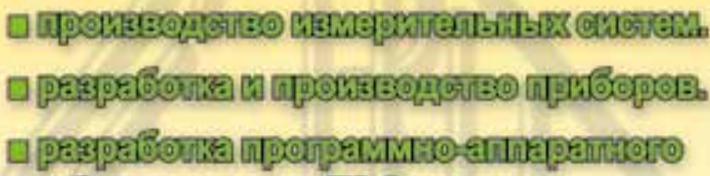

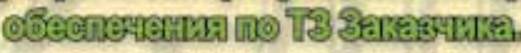

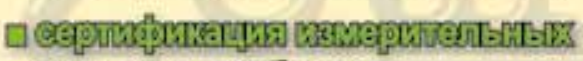 लrerem a apropoper.}

\section{Инструментальныерешения замдам заказиика]}

125130, г. Москва, ул. Клары Цеткин, д. 33 корп. 35 www.rudshel.ru, e-mail: adc@rudshel.ru тел./факс: (495) 787-6367, 787-6368
СИЭл159-356Б не имеет никаких повреждений. Проверка электрических параметров интегральной схемы показала идентичность характеристик до и после испытаний.

Такие результаты дают основания утверждать, что применение жидкости БЛ-П для заполнения датчиков давления со встроенной защитной мембраной, несмотря на высокую стоимость жидкости, оправдано гарантией долговременной стабильности характеристик датчиков. Кроме того, габаритные размеры датчиков имеют тенденцию к уменьшению, так что расход дорогой жидкости не превысит 1-3 мл на датчик.

\section{ЗАКЛЮЧЕНИЕ}

На примере датчиков давления проведен анализ факторов, препятствующих активным разработкам высокоточных контрольно-измерительных МЭМС-датчиков и налаживанию их стабильного производства:

- отмечены недостатки широко применяемой технологии нанесения кремнийорганических компаундов на поверхность кристалла чувствительного элемента и предложен вариант нанесения, радикально повышающий качество приборов;

- теоретически и экспериментально доказана недопустимость применения кремнийорганических жидкостей для заполнения МЭМС-датчиков с разделительной мембраной.

Предложены практические решения по устранению проанализированных проблем путем внедрения специально разработанного для защиты чувствительных элементов измерительных сенсоров компаунда СИЭЛ 159-356Б и фторорганической жидкости БЛ-П.

\section{ЛИТЕРАТУРА}

1. Сергеева Н. А, Цивинская Т. А., Шахнов В. А. Контрольно-измерительные МЭМС с использованием малогабаритных чувствительных элементов из монокристаллического кремния // Датчики и системы. 2016. № 3. С. 32-39.

2. Аваева Л. Г, Сергеева Н. А., Милешин С. А., Цивинская Т. А. Анализ проблем производства кристаллов чувствительных элементов из монокристаллического кремния для сенсорных систем // Датчики и системы. 2017. № 5. C. 25.

3. Андреев К. А., Власов А. И., Шахнов В.А. Кремниевые преобразователи давления с защитой от перегрузок // Датчики и системы. 2014. № 10. С. 54-57.

4. Илларионов В.Н., Нанушьян С. Р., Нестеров В.Б. Исследование влияния защитных кремнийорганических материалов на коррозию алюминиевой металлизации интегральных схем. - Биохим. Электронный ресурс. Адрес доступа: http://www.biohim.ru/library/956.php. Дата обращения 04.04.2018

5. Готра 3. Ю. Технология микроэлектронных устройств. М.: Радио и связь, 1991. 528 с. 


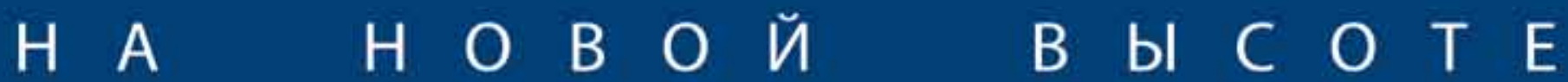

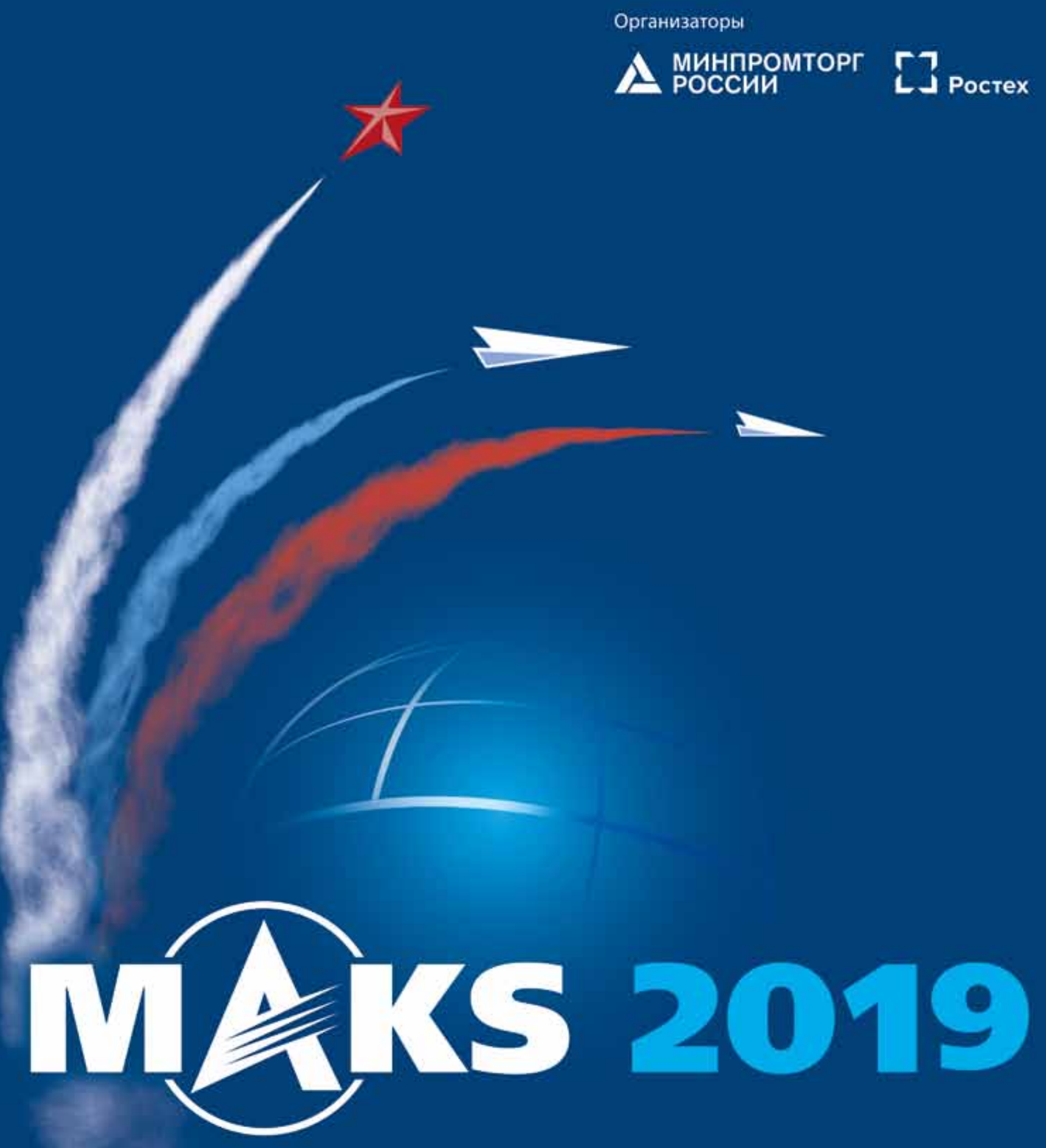

ЖУКОВСКИЙ - 27 АВГУСТА - 1 СЕНТЯБРЯ 